\title{
Grazer-induced changes in the desmid Staurastrum
}

\author{
Karen Wiltshire ${ }^{1,2}$, Maarten Boersma ${ }^{1,2}$ \& Barbara Meyer ${ }^{1}$ \\ ${ }^{1}$ Max-Planck-Institut für Limnologie, Postfach 165, D-24306 Plön, Germany \\ ${ }^{2}$ Alfred-Wegener-Institut für Polar- und Meeresforschung, Biologische Anstalt Helgoland, \\ Postfach 180, 27483 Helgoland, Germany \\ Tel: +49 4725 819238. Fax: +494725 819283.E-mail: kwiltshire@awi-bremerhaven.de
}

Received 13 August 2002; in revised form 13 August 2002; accepted 18 September 2002

Key words: food quality, Daphnia, kairomone

\begin{abstract}
In aquatic environments, predator kairomones have been shown to affect morphology of prey species. Past work on the interaction between zooplankton and phytoplankton was based mainly on the Daphnia-Scenedesmus model. Algae of the genus Staurastrum can produce mucilage, causing cell clumping and settling out of the water column. These clumps are too large to be eaten by daphniids. Thus, we hypothesised that this may be a grazer defence. We investigated whether Daphnia magna induces the formation of mucus globules in Staurastrum, how this occurs, and if the formation of clumps inhibits growth in juvenile Daphnia. Eight strains of Staurastrum were used to check whether mucus extrusion is induced by the presence of Daphnia or possibly by a chemical excreted by Daphnia magna. None of the strains reacted to the presence of Daphnia water alone, animals had to be present to induce clumping. Mechanical action (gentle stirring) caused the same strains to clump. The ecological relevance of clumping was then investigated. The different Staurastrum strains were used as food in a growth experiment with ecologically relevant densities of neonates of Daphnia hyalina. These small daphniids did not cause the same clumping observed for Daphnia magna when present in experiments at high densities. We observed that juvenile daphniids grew less well on strains with larger cell size.
\end{abstract}

\section{Introduction}

Perhaps one of the most interesting phenomena in the co-evolution of planktonic micro-algae and their grazing zooplankter 'predators' is the question of algal defence against these predators (see Havel, 1987; Smetacek, 2001). Indeed, in recent years, the phenomenon of predator-induced changes in prey organisms has become a hot topic in research in ecology (Larsson \& Dodson, 1993; Tollrian \& Harvell, 1999). Especially in the last decade, it has become increasingly clear that chemicals excreted by predators (kairomones) can influence a wide range of characteristics in their prey species. In aquatic environments, predator kairomones have been shown to affect morphology, life-history traits and behaviour of prey species (reviewed by Harvell, 1990; Larsson \& Dodson, 1993; Lass \& Spaak, 2003). These predator-prey commu- nication links have been found throughout aquatic foodwebs. They include the relationship between piscivorous fish and planktivorous fish (e.g. Nilsson et al., 1995; Gliwicz et al., 2001) relationships between planktivorous fish and zooplankton (e.g. Stibor, 1992; Reede, 1995) and between invertebrate predators and zooplankton (e.g. Stemberger \& Gilbert, 1987; Kusch, 1993; Lüning, 1995; Tollrian, 1995). Interestingly, they also have been shown between zooplankton and algae (Hessen \& van Donk, 1993; Lampert et al., 1994; Wiltshire \& Lampert, 1999).

Most of the studies on the effects of kairomones have concentrated on the link between planktivorous fish and herbivorous zooplankton (Daphnia). Other interactions have been studied in much less detail. The herbivorous zooplankton-algae interface has, in particular, received relatively little attention. With respect to the ecological side of this interaction, work by such 


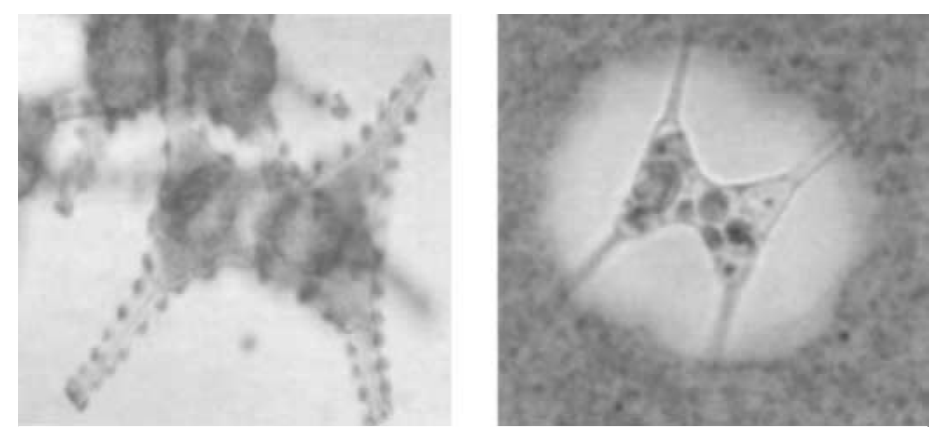

Figure 1. Globules of polysaccharides and mucous in Staurastrum.

authors as Hessen \& van Donk (1993), Lampert and co-workers (1994), Rengefors at al. (1998), Lürling (1999a) and Wiltshire \& Lampert (1999) essentially covers the whole body of knowledge available to us. The chemical characterisation of the substances involved has been merely covered by von Elert \& Franck (1999), Wiltshire \& Lampert (1999) and van Holthoon et al. (2003).

Considering the vast evolutionary significance of a defence reaction of algae to predators, the fact that the literature cited above deals almost exclusively with the interactions of Scenedesmus algae and Daphnia, is very limited. Essentially all of the work on morphological changes in algae as a result of predation by zooplankters used the Daphnia-Scenedesmus system as a model. This system seems to be rather robust, and the presence of daphniids in the water generally causes an induction of the formation of coenobia in Scenedesmus. However, when workers ventured outside this narrow path, they found that water previously inhabited by Daphnia did not induce the formation of colonies or aggregates in the cyanobacteria, Oscillatoria agardhii, Aphanizomenon flos-aquae, or Microcystis aeruginosa, no colony formation in the diatom Asterionella formosa, only very small changes inSynedra tenuis, and no changes in 8 of 23 Scenedesmus strains studied (Lürling, 1999b). Hence, the phenomenon seems more a peculiarity of non-spiny Scenedesmus and closely related Coelastrum than a phenomenon that might be of widespread ecological importance.

The literature shows that the desmids belonging to the genus Staurastrum are often resistant to grazing by zooplanktors under natural conditions (Scharf, 1995; Hansson \& Tranvik 1996; Boeing et al., 1998). This led us to the consideration that this could be related to size, shape and/or the fact that the desmids can produce mucilagenous sheaths (Surek \& von Seng- busch, 1981; Surek, 1983). With regard to the latter phenomenon, we had observed in previous unpublished work on the desmid genus Staurastrum isolated from natural lakes in Northern Germany, that this alga sometimes produces large amounts of mucilage (Fig. 1). This can result in the algae clumping together and settling out of the water column. These large clumps were definitely too large to be eaten by daphniids and therefore we hypothesised that this could be an induced defence to avoid being grazed. Thus, in this study we set out to investigate, whether: (a) Daphnia induces the formation of the mucus globules in Staurastrum, (b) how this occurs, and (c) if the formation of the resulting clumps inhibits growth in juvenile Daphnia. Eight different strains of Staurastrum isolated from different lakes were used in this study.

\section{Material and methods}

\section{Staurastum strains}

Different Staurastrum strains had been previously isolated from the lakes in Northern Germany all of which had a resident population of daphniids. The exact details of the strains are given in Table 1. All the Staurastrum cultures used in this experiment were cultured in WC medium in Erlenmeyer vessels at 20$21^{\circ} \mathrm{C}$ and a light rhythm of $12 \mathrm{~h}$ day and night, with light amounts of $150 \mu \mathrm{mol} \mathrm{m} \mathrm{m}^{-2} \mathrm{~s}^{-1}$.

\section{Experiment 1: Induction of clumps using Daphnia}

The induction of clumping in Staurastrum by Daphnia was investigated by exposing three times $50 \mathrm{ml}$ of algal solution (WC medium) to 5 individuals of Daphnia magna (size $3 \mathrm{~mm}$ ), incubated for four hours at $20-21^{\circ} \mathrm{C}$ under $150 \mu \mathrm{mol} \mathrm{m} \mathrm{m}^{-2} \mathrm{~s}^{-1}$ of light in 100 $\mathrm{ml}$ glass Erlenmeyer vessels. To check whether the 
Table 1. Details of Staurastrum cultures used in experiments. The size was established as equivalent spherical diameter over a period of 5 days, using an electronic particle counter. Standard error in brackets

\begin{tabular}{|c|c|c|}
\hline Strain no: & Strain details & Average size $(\mu \mathrm{m})$ \\
\hline 1 & Staurastrum boreale W.et G.S.West; SAG* number B4.94; & $14.63(0.77)$ \\
\hline 2 & Staurastrum pingue Teiling var. pingue; B. Meyer MPIL Plön**; & $19.72(0.42)$ \\
\hline 3 & Staurastrum pingue Teiling var. pingue; SAG* number B5.94; & $19.97(0.82)$ \\
\hline 4 & $\begin{array}{l}\text { Staurastrum pseudotetracerum (Nordstedt) W.et G.S.West; B. } \\
\text { Meyer MPIL Plön**; }\end{array}$ & $11.98(0.07)$ \\
\hline 5 & $\begin{array}{l}\text { Staurastrum cingulum (W.et G.S.West) G.M. Smith var.obesum } \\
\text { G.M.Smith; B. Meyer MPIL Plön**; }\end{array}$ & $11.58(0.05)$ \\
\hline 6 & $\begin{array}{l}\text { Staurastrum pseudotetracerum (Nordstedt) W.et G.S.West; SAG* } \\
\text { number B5.94; }\end{array}$ & $12.27(0.05)$ \\
\hline 7 & $\begin{array}{l}\text { Staurastrum tetracerum (Kützing) Ralfs var.tetracerum; SAG* } \\
\text { number B7.94; }\end{array}$ & $9.20(0.01)$ \\
\hline 8 & Staurastrum chaetoceras; B. Meyer MPIL Plön**; & $16.68(0.30)$ \\
\hline
\end{tabular}

* Sammlung von Algenkulturen Universität Göttingen. ** Culture collection B.Meyer MPIL-Plön.

phenomenon of mucus extrusion is indeed induced by a chemical excreted by Daphnia or whether Daphnia needs to be physically present to induce the change, the strains were also incubated in water that had been previously contained a dense colony of Daphnia (see methods described by Lampert et al., 1994).The control was the algal culture on its own.

\section{Experiment 2: Induction of clumps due to mechanical agitation}

After it had been ascertained in Experiment 1 which Staurastrum strains evinced clumping in the presence of Daphnia, we investigated whether the same phenomenon could be observed when the algal cultures were gently stirred. This was achieved by incubating three times $50 \mathrm{ml}$ of algal solution with and without the addition of a magnetic stirring rods $(5 \mathrm{~mm} \times$ $2 \mathrm{~mm}$ ) to the cultures on a multi-stirring plate and observing the outcome. The controls were unstirred cultures. Again the cultures were incubated for four hours at $17^{\circ} \mathrm{C}$ under $150 \mu \mathrm{mol} \mathrm{m}{ }^{-2} \mathrm{~s}^{-1}$ of light. The stirring rate was at the lowest setting at which the rods still turned.

\section{Experiment 3: effect of Staurastrum on Daphnia growth rates}

The different Staurastrum strains were used as food in a growth experiment with neonates of Daphnia hyalina. D. hyalina was used in the growth experiments because these animals are small, and hence more likely to have problems with larger particles, and because most of the Staurastrum strains used in this study were collected from habitats were they co-occur with the smaller Daphnia species.

The Daphnia hyalina clone used in the growth experiment, originally collected from Lake Constance, Germany, had been cultured in the laboratory for many years. All experiments were carried out in filtered Schöhsee water $(0.45 \mu \mathrm{m}$ pore size membrane filter). Juvenile animals were collected from a stock culture, and placed individually in 200-ml containers. They were fed a suspension of Scenedesmus obliquus (1.5 $\mathrm{mg} \mathrm{C} \mathrm{L-1}$ at $20^{\circ} \mathrm{C}$ ). Media were changed daily. The day-night cycle consisted of $16 \mathrm{~h}$ light and $8 \mathrm{~h}$ of darkness. Third brood juveniles of these animals were collected and served as the experimental animals.

Third brood neonates produced by the mothers of the experimental animals were collected within $12 \mathrm{~h}$ of birth, placed in 100-ml vessels, and kept in these vials for 5 days. Media were changed daily and the temperature and light conditions were identical to the ones their mothers had been exposed to. Every vessel contained four animals. The initial weight of the animals was established by grouping four neonates from each clutch at the start of the experiment. After 5 days, the animals were harvested, and their dry weight was estimated. For dry weight analyses the animals were transferred to small aluminium weighing boats, dried for $24 \mathrm{~h}$ at $60^{\circ} \mathrm{C}$, stored in a desiccator, and weighed to the nearest $0.1 \mu \mathrm{g}$ using an electronic microbalance. Somatic growth rates were computed and analysed. 
Table 2. Reaction of Staurastrum cultures to experimental treatments

\begin{tabular}{lcccc}
\hline $\begin{array}{l}\text { Treatment } \\
\text { Strain no. }\end{array}$ & + Daphnia & - Daphnia & + Stirring & - Stirring \\
\hline 1 & NR & NR & NR & NR \\
2 & NR & NR & NR & NR \\
3 & NR & NR & NR & NR \\
4 & ATS & NR & ATS & NR \\
5 & ATS & NR & ATS & NR \\
6 & CS & NR & CS & NR \\
7 & CS & NR & CS & NR \\
8 & NR & NR & NR & NR \\
\hline
\end{tabular}

$\mathrm{NR}=$ No reaction $; \mathbf{A T S}=$ Attached to vessel sides $\mathbf{C S}=$ Clumping and settlement out.

\section{Results}

Incubation of Staurastum strains with Daphnia

Of the eight strains tested in this study four did not react to the presence of Daphnia at all (Table 2). These were strains $1,2,3$ and 8 (see also Table 1). Two strains (6 and 7) formed dense clumps of algae, and were found settled to the bottom and attached to the sides of the Erlenmeyer vessels in which the experiments were carried out. The two remaining strains (4 and 5) also stuck to the sides of the vessels to some degree although they did not clump. None of the strains reacted to the presence of Daphnia water alone.

\section{Stirring}

Since the outcome of Experiment 1 showed that Staurastrum only excretes mucus (causing clumping) when the grazers are physically in the presence of the algae and is not induced by the Daphnia water; we hypothesised that this was a result of the motion of the animals. That is, that mechanical action might also induce this phenomenon. In Experiment 2 we tested this and indeed found that gentle stirring also resulted in the formation of the glue, and hence the formation of aggregates (see Table 2).

\section{Growth experiment}

In the growth experiment, we observed that the mechanical action of the small daphniids was too low per vessel volume to induce the clump formation in the Staurastrum cells. However, the growth of the daphniids on the different strains varied significantly, and

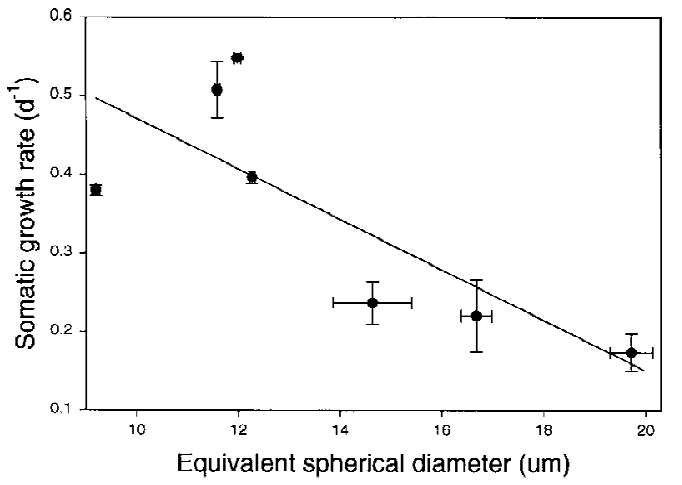

Figure 2. Somatic growth rates of Daphnia in relation to the size of Staurastrum cells. The regression line explains $56 \%$ of the variance, which is significant at $p<0.05$. Error bars indicate standard errors.

was significantly correlated with the size (equivalent spherical diameter) of the cells (Fig. 2). That is: the larger the cell size (see Table 1) the worse the daphniids did on the food. When the animals were fed on Staurastrum pingue (strain 3 in Table 1, isolated from the Keller Lake in Northern Germany) survival was very low, and no animals survived to day five of the experiment.

\section{Discussion}

Although it is known that the desmids can secrete large amounts of mucilage, little literature is available on the processes involved in, and the control of this (Surek \& von Sengbusch, 1981; Surek 1983; Fukami et al., 1990). Since the literature also shows that Staurastrum is often grazer-resistant in lakes (Scharf, 1995; Hansson \& Tranvik, 1996; Boeing et al., 1998 etc.) the question as to whether Staurastrum mucilage production was important to grazers and induced in the presence of the grazer was self-evident. In this work we have shown that formation of the mucus globules was indeed induced by the physical presence of grazing daphniids. However, unlike the reaction of, for example Scenedesmus, which forms coenobia in the presence of Daphnia and Daphnia water (Hessen \& van Donk, 1993; Lampert et al., 1994; Wiltshire \& Lampert, 1999), Staurastrum did not react to the water in which Daphnia were previously held. We showed that gentle mechanical stirring could also induce the formation of the same sticky clumps. This means that it is difficult to envisage how this can be a clear predator avoidance strategy, as the algae essentially only react when the predator is so 
close/numerous that the water is actually turbulent as a result of the Daphnia filtering action. In effect, this probably means that this reaction is too late to save an isolated individual and more likely to be important in dense populations of algae and predators. Staurastrum pseudotetracerum (SAG) and Staurastrum tetracerum (strains 6 and 7, respectively) were the algae, which clumped as a result of low mechanical action and the presence of high concentrations of Daphnia magna. Strains 4 and 5 (Staurastrum pseudotetracerum (Plön) andStaurastrum cingulum, respectively) also became sticky, but to a lesser degree by Daphnia or stirring. Interestingly, these algae were smaller than the rest (see Table 1) and clumping/becoming sticky might be a useful anti-predation strategy in the smaller algae. This may be particularly important in the light of the results of the feeding experiment. In that experiment with ecologically relevant concentrations of algae and a small daphniid (Daphnia hyalina), we observed that the strains differed in their suitability as food for Daphnia and that this was related to size. The smaller the cells the more suitable they were as food. There was a decreasing suitability as food for Daphnia with size increase. One strain was completely unsuited: all of the animals were dead after two days, and most of them died within the first $24 \mathrm{~h}$ of the experiment, a period much too short for starvation. This is of interest as mostly everything under $30 \mu \mathrm{m}$ is considered edible for daphniids, and to date almost no reports exist on differences in suitability as food within the edible size range. Our results suggest that the optimal food size for juvenile daphniids is actually around $10 \mu \mathrm{m}$. This is of great ecological relevance and backed up by several studies on grazing of algal populations in lakes which show that Staurastrum is generally unsuitable food because it is too large to be eaten (Scharf, 1995; Hansson \& Tranvik, 1996; Coesel, 1997; Boeing et al., 1998). If, in addition, the algae were to produce mucilaginous sheaths like other desmids, e.g., Cosmarium and Cosmocladium (Surek, 1983; Coesel, 1997) they may also prove difficult to ingest and difficult to digest (see Porter, 1976).

None of the Staurastrum strains showed any signs of clumping in the growth experiment with Daphnia hyalina, even though the incubation time was $24 \mathrm{~h}$ instead of the $4 \mathrm{~h}$ in the induction experiments. Thus, we could not really investigate the effect of the clumped cells on growth of the daphniids. The densities of the daphniids in the incubations were chosen such that they represented more or less natural ones, because at the same time we wanted to investigate the ecological relevance of the clumping. Had we carried out the same experiment again with pre-induced algae the results probably would have been different, as especially the smaller strains showed signs of clumping. Most likely, growth on strains 4-7 would have been considerably less, whereas the growth rates on the other strains should not have been affected. Nevertheless, the result obtained here probably represents a natural situation more than the results of an experiment with clumped algae.

As desmids, like other green algae and diatoms, produce mucous under a variety of different environmental conditions depending on factors such as light, temperature and age of culture (see Surek, 1983) the production is most probably not only a defence reaction. But rather, in evolutionary terms it also has proven useful as a defence mechanism. This is the same phenomenon as observed for the alga Scenedesmus in its reaction to Daphnia. Scenedesmus forms colonies as part of its life cycle and as a result of many environmental stimulants - one of which is its grazer (see Wiltshire \& Lampert, 1999 for overview). Hence, it is difficult to assess whether the induction of colony formation indeed decreases the suitability of the algae as food for herbivorous zooplankton. Obviously, when the colonies become very large or heavily spined they are a food source of lower quality for the zooplankters (Hessen \& van Donk, 1993). When comparing single cells and coenobia of S. obliquus, Lampert et al. (1994) found no differences in the uptake between colonies and single cells by Daphnia magna, nor did Lürling (1996) for D. pulex. However, the smaller species $D$. cucullata seemed to have problems with the colonies. It seems to be the case that especially smaller Daphnia species, or juveniles of larger species have some problems with larger cells (in the case of Staurastrum), spined cells (Desmodesmus), or with colonies (Lürling \& van Donk, 1996). However, the ecological relevance of this is difficult to assess, especially as the results in the literature are not consistent. Nevertheless, the fact that Scenedesmus is almost the only alga reacting to 'infochemicals' of Daphnia, combined with the fact that in many lakes it only comprises a relatively low percentage of the phytoplankton community, suggests that the ecological relevance of colony induction by zooplankters is not high. Unlike Scenedesmus, the ecological relevance of Staurastrum size differences is clearer, as it has already been shown to be important in situ and the settling out of larger Staurastrum from the pelagic food chain to the benthos an accepted fact (Coesel, 
1997). As to whether this is related to the formation of clumps due to the mechanical agitation of the water by zooplankters is unknown. Future work on clumping in Staurastrum should include a whole range of Daphnia species, sizes and densities in order to categorically answer the question on the inducibility by Daphnia. Moreover, much needs to be still done to differentiate the relevance of both mucilage production and size in preventing desmid ingestion and digestion, in order to evaluate the role of predator defence strategies of Staurastrum in situ.

\section{Acknowledgements}

We thank Heinke Buhtz and Regina Leipnitz for their assistance during the experiments. Winfried Lampert is thanked for stimulating discussions. KHW and MB were partly supported by contract ENV4-CT970402 (SNIFFS) within the framework of the European Commission's Environment and Climate Program.

\section{References}

Boeing, W. J., A. Wagner, H. Voigt, T. Deppe \& J. Benndorf, 1998. Phytoplankton responses to grazing by Daphnia galeata in the biomanipulated Bautzen reservoir. Hydrobiologia 398: 101-114.

Coesel, P. F. M., 1997. The edibility of Staurastrum chaetoceras and Cosmarium abbreviatum (desmidiaceae) for Daphnia galeata/hyalina and the role of desmids in the aquatic foodweb. Aquat. Ecol. 31: 73-78.

Fukami K., S. Ohara \& Y. Ishida, 1990. Effect of extracellular organic carbon from phytoplankton on the community structure of oligotrophic bacteria. Arch. Hydrobiol. Beih. Ergebn. Limnol. 34: 43-48.

Gliwicz, Z. M., P. Dawidowicz, A. Jachner \& W. Lampert, 2001. Roach habitat shifts and foraging modified by alarm substance 2. Reasons for different responses of fish in field and laboratory studies. Arch. Hydrobiol. 150: 377-392.

Hansson L. A. \& L. J. Tranvik, 1996. Quantification of invertebrate predation and herbivory in food chains of low complexity. Oecologia 108: 542-551.

Harvell, C. D., 1990. The ecology and evolution of inducible defenses. Quart. Rev. Biol. 65: 323-340.

Havel, J. E., 1987. Predator-induced defenses: a review. In Kerfoot, W. C. \& A. Sih (eds), Predation: Direct and Indirect Impacts on Aquatic Communities. University Press, New England, Hanover: 263-278.

Hessen, D. O. \& E. van Donk, 1993. Morphological changes in Scenedesmus induced by substances released from Daphnia. Arch. Hydrobiol. 127: 129-140.

Kusch, J., 1993. Induction of defensive morphological changes in ciliates. Oecologia 94: 571-575.
Lampert, W., K. O. Rothhaupt \& E. von Elert, 1994. Chemical induction of colony formation in a green alga (Scenedesmus acutus) by grazers (Daphnia). Limnol. Oceanogr. 39: 1543-1550.

Larsson, P. \& S. I. Dodson, 1993. Chemical communication in planktonic animals. Arch. Hydrobiol. 129: 129-155.

Lass, S. \& P. Spaak, 2003. Chemically induced anti-predator defences in plankton: a review. Hydrobiologia 491: 221-239.

Lüning, J., 1995. Life-history responses to Chaoborus of spined and unspined Daphnia pulex. J. Plankton Res. 17: 71-84.

Lürling, M., 1999a. Grazer-induced coenobial formation in clonal cultures of Scenendesmus obliquus (Chlorococcales, Chlorophyceae). J. Phycol. 35: 19-23.

Lürling, M., 1999b. The smell of water; Grazer-induced colony formation in Scenedesmus. Ph.D., Agricultural University, Wageningen: $270 \mathrm{pp}$.

Lürling, M. \& E. van Donk, 1996. Zooplankton-induced unicellcolony transformation in Scenedesmus acutus and its effect on growth of herbivore Daphnia. Oecologia 108: 432-437.

Nilsson, P. A., C. Brönmark \& L. B. Pettersson, 1995. Benefits of a predator-induced morphology in crucian carp. Oecologia 104: 291-296.

Porter, K. G., 1976. Enhancement of algal growth and productivity by grazing zooplankton. Science 192: 1332-1334.

Reede, T., 1995. Life history shifts in response to different levels of fish kairomones in Daphnia. J. Plankton Res. 17: 1661-1667.

Rengefors, K., I. Karlsson \& L. A. Hansson, 1998. Algal cyst dormancy: a temporal escape from herbivory. Proc. R. Soc. Lond. Ser. B 265: 1353-1358.

Scharf, W., 1995. Staurastrum quadridentatum spec.nov. (chlorophyta, Desmidiaceae): A new desmid species from the plankton. Arch. Hydrobiol. Suppl. 109: 1-10.

Stemberger, R. S. \& J. J. Gilbert, 1987. Defenses of planktonic rotifers against predators. In Kerfoot, W. C. \& A. Sih (eds), Predation: Direct and Indirect Impacts on Aquatic Communities. University Press, New England, Hanover: 227-239.

Stibor, H., 1992. Predator-induced life-history shifts in a freshwater cladoceran. Oecologia 92: 162-165.

Smetacek, V., 2001. A watery arms race. Nature 411: 745.

Surek, B., 1983. Mucilage regeneration in the green alga Cosmocladium saxonicum de Bary (Desmidiaceae): A light microscopic and quantitative study. Brit. Phycol. J. 18: 73-81.

Surek, B. \& P. von Sengbusch, 1981. The localisation of Galactosyl residues and Lectin receptors in the mucilage and cell walls of Cosmocladium saxonicum (Desmidiaceae) by means of fluorescent probes. Protoplasma 108: 149-161.

Tollrian, R., 1995. Predator-induced morphological defenses: costs, life history shifts, and maternal effects in Daphnia pulex. Ecology 76: 1691-1705.

Tollrian, R. \& C. D. Harvell (ed.). 1999. The Evolution of Inducible Defenses. Princeton University Press, Princeton.

van Holthoon, F. L., T. A. van Beek, M. Lürling, E. van Donk \& A. de Groot, 2003. Colony formation in Scenedesmus: a literature overview and further steps towards the chemical characterisation of the Daphnia kairomone. Hydrobiologia 491: 241-254.

von Elert, E. \& A. Franck, 1999. Colony formation in Scenedesmus: grazer-mediated release and chemical features of the infochemical. J. Plankton Res. 21: 789-804.

Wiltshire, K. H. \& W. Lampert, 1999. Urea excretion by Daphnia: A colony-inducing factor in Scenedesmus? Limnol. Oceanogr. 44: 1894-1903. 